\title{
Doctoral Education and the Academic Job Market in Planning: 2017-2018
}

Joanna Ganning

Cleveland State University, j.ganning@csuohio.edu

Follow this and additional works at: https://engagedscholarship.csuohio.edu/urban_facpub

Part of the Urban Studies and Planning Commons

How does access to this work benefit you? Let us know!

\section{Repository Citation}

Ganning, Joanna, "Doctoral Education and the Academic Job Market in Planning: 2017-2018" (2018). All Maxine Goodman Levin School of Urban Affairs Publications. 01231550.

https://engagedscholarship.csuohio.edu/urban_facpub/1550 


\section{September 7, 2018 Doctoral Education and the \\ Prepared by: Academic Job Market in Joanna Ganning, Ph.D. Planning: 2017-2018}

With research assistance by:

Georgina Figueroa Lydia Benish

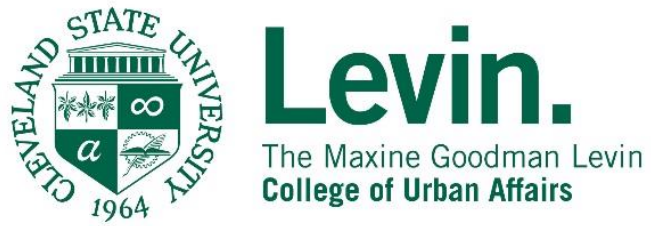




\section{Executive Summary}

This 2017-2018 report on doctoral education and the academic job market in Planning was motivated by a series of questions about the size of and trends in the academic job market, the number of graduates, and their engagement in academic employment. Based on a survey of doctoral programs in Planning and an analysis of academic jobs in Planning posted during the 2017-2018 academic year, this report presents the following findings:

- How many Planning PhDs graduate each year?

According to the academic year 2017-2018 survey, approximately 294. The average program graduates 4.67 per year.

- How many new PhDs secure academic jobs in Planning?

Approximately $46 \%$ of graduates secure academic jobs in Planning, but less than $20 \%$ of graduates secure tenure-track positions advertised through ASCP. The number of graduates finding academic positions (either tenure-track or not) far outnumbers the jobs posted through ACSP for which new PhDs would be eligible, leading to the hypothesis that a not unsubstantial number of graduates find employment other ways, such as through ongoing appointments at their home institutions or with allied fields.

- How many academic jobs in Planning are posted each year?

In 2017-2018, institutions posted 114 academic jobs for positions starting in Fall 2018. Of those, 91 were in the U.S., 12 were in Canada, and 11 were in other countries. Approximately 70 were open to new PhDs; 51 were tenure-track jobs.

- Which specializations were popular this year?

During academic year 2017-2018, the job market most strongly favored:

Environmental and Sustainability Planning; Transportation, Land use, and Urban

Design; and Community Development.

Disaster Management and Public Administration saw the fewest job announcements.

- How well do PhD program specializations align with the job market?

Like the job market, $\mathrm{PhD}$ programs frequently focus on Environmental and

Sustainability Planning, and Transportation, Land Use and Urban Design. Programs

least commonly focus on Urban Policy, GIS/Spatial Analysis, Landscape

Architecture, and Geography.

- How much teaching experience is "normal" for new PhDs?

Nearly three-quarters of programs ensure that all or most students gain teaching experience. However, across programs, training in curriculum design is limited.

- How many programs support or require students to publish?

The survey results show that in $70 \%$ of programs, all or most $\mathrm{PhD}$ students publish prior to graduation. However, the survey does not inform on how many articles students publish, or how often they are leading authors, or about whether they publish in ranked journals.

Taken together, the results indicate that the academic job market in Planning was quite competitive in the 2017-2018 academic year. Planning PhD programs produced more graduates than job openings, and those graduates generally have both teaching and research experience. Students will find uneven job opportunity across specializations, with some seeing more postings than others. In future iterations of this report it will become clear whether and how much these focal areas change over time. 


\section{Introduction}

This report presents a two-part analysis of Planning $\mathrm{PhD}$ programs and the Planning academy job market during the 2017-2018 academic year. The study was motivated by two descriptive research questions:

1. What does the Planning academy job market look like, and how much does it change from year to year?

2. Approximately how many PhDs graduate each year and where do they go?

Through the spring and summer of 2018, PhD program directors/coordinators (or other relevant members if a coordinator could not be identified or reached) were surveyed in 63 academic departments throughout the United States. Respondents provided information about the number of graduates, graduate placement at academic institutions, program specializations, publishing requirements for students, and the teaching opportunities available during $\mathrm{PhD}$ programs.

The survey results are paired with data about the academic job market in Planning, gathered from ACSP emails and the ACSP online job postings from August 2017-July 2018. While the job market data is publicly available, it has not been tracked historically and is not available historically from ACSP. The database was designed to track not only the number of positions by rank, but also by specialization, location, and by other features. Both the survey and the job postings database are designed to continue over a five-year period.

An analysis of these data reveals a competitive academic job market in Planning, with more graduates than positions, and with graduates holding both teaching and research experience. The popularity of specialization varies across program offerings and the job market, although both favor Environmental and Sustainability Planning and Transportation, Land Use and Urban Design. This report presents the data collection methods; results; shortcomings of the research; and a conclusion. Results are presented in three sub-sections: number of graduates and job openings; specializations; and graduates' teaching and research experience.

\section{Methods}

\section{Survey Instrument}

The survey instrument used for this project (and approved by the Institutional Review Board at Cleveland State University) contains 13 questions. Respondents signified informed consent. Informed consent was necessary because by publishing the respondent identification strategy, anonymity could not be guaranteed. Respondents were informed that survey data would be reported in aggregated versions but that university-level responses might also be shared. Respondents were asked to report data for programs from which graduates might pursue careers in the Planning academy.

Questions then shift to data collection about the graduates. This information was solicited on a semester-by-semester basis to improve accuracy but is reported as aggregated to the academic year. 
- How many students graduated during Academic Year 2017-2018?

- How many of those graduates accepted positions at academic institutions? Which academic institutions?

The second group of questions focuses on $\mathrm{PhD}$ programs rather than students. The first program-related question asks respondents to identify program specializations from a list. The list provided was taken from Sen, Umemoto, Koh, and Zambonelli (2017) ${ }^{1}$. Since, Brinkley and Hoch have published a paper ${ }^{2}$ that focuses on specializations in Planning education, which may be useful for future iterations of this survey. Survey respondents wrote in specializations if those provided in the list did not suitably reflect their program.

As teaching experience is sometimes given as a preferred skill in academic job postings, respondents were then asked to provide information about the teaching opportunities available to $\mathrm{PhD}$ students. Respondents answered multiple choice questions about the teaching opportunities offered to students, and the share of $\mathrm{PhD}$ students who engage in those experiences.

Finally, respondents were asked two multiple choice questions about the role of publishing in doctoral education. The potential answers to the second question are listed below to make clear the aim of the question.

- To what extent do $\mathrm{PhD}$ students in your program publish prior to graduation? (Where publishing includes having work accepted and in press, or fully published)

- Describe the role of publishing in doctoral education in your program:

$\circ$ Publishing is a requirement of our program

- Students are required to produce publishable research, but publication is not required

- Students are encouraged to publish

- Publishing is not a focal point of our program

\section{Participant Identification}

$\mathrm{PhD}$ programs were identified by a review of departmental websites for all Planning Accreditation Board (PAB) accredited Master's degree programs. This list was supplemented and cross-referenced with the ACSP Guide to Undergraduate and Graduate Education in Urban and Regional Planning, 2014 Edition (the most recent edition available online ${ }^{3}$ ). This approach yielded $63 \mathrm{PhD}$ programs, which are listed in the Appendix ${ }^{4}$. The departmental websites similarly yielded the contact list for identified program directors/coordinators, and, if none could be identified or reached, department chairs. In some cases, identified participants replied

\footnotetext{
${ }^{1}$ Sen, S., Umemoto, K., Koh, A., \& Zambonelli, V. (2017). Diversity and social justice in planning education: A synthesis of topics, pedagogical approaches, and educational goals in planning syllabi. Journal of Planning Education and Research, 37(3), 347-358.

${ }^{2}$ Brinkley, C., \& Hoch, C. (2018). The Ebb and Flow of Planning Specializations. Journal of Planning Education and Research, 0739456X18774119.

${ }^{3}$ https://cdn.ymaws.com/www.acsp.org/resource/collection/6CFCF359-2FDA-4EA0-AEFAD7901C55E19C/2014 20th Edition ACSP Guide.pdf

${ }^{4}$ One challenge of this study came in defining "Planning PhD programs." Admittedly the approach taken may overlook some programs, especially those that exist within Geography Departments or similar. Readers are encouraged to submit names of overlooked programs.
} 
to advise that program leadership had changed or that they had been misidentified as the program coordinator. The participant contact list was amended with this feedback.

\section{Dissemination and Participation}

The survey was conducted online using the Microsoft Forms survey tool. The solicitation to participate was sent out three times during the summer of 2018: May 16, May 30, and July 2. The last of these solicitations went only to the smaller group of programs which had not yet participated. The survey closed on July 31 .

Of the 63 programs contacted, 28 fully participated. A $29^{\text {th }}$ program responded but only to clarify that Planning exists as a track in a Geography $\mathrm{PhD}$ program and has not attracted a Planning-focused student in some years. This response was discarded. For one of the 28 programs, two faculty members participated. Their responses were condensed into a single response with discrepancies resolved via email.

\section{Job Bank Data}

All academic jobs posted on the ACSP website were compiled in an Excel database between July 2017 and July 2018. Efforts were made to monitor the Planners 2040 Facebook page as well but doing so systematically proved more challenging. In at least one case, a job was posted to the Planners 2040 Facebook group but not the ACSP page, justifying the effort. Characteristics of each job were recorded in pre-determined fields in a database. These fields include (but are not limited to) job title, name of the institution and department, rank and role, desired specialization and whether the position is tenure-track.

\section{Results}

The data gathered through the survey and job bank data is combined and synthesized to produce the following narrative. The results are presented in three sub-sections: numbers of graduates and job openings; specializations; and graduates' experience in teaching and research.

\section{By the Numbers: Graduates and Job Openings}

The 28 participant departments identified 131 graduates, averaging 4.67 graduates per program during the 2017-2018 academic year. The distribution of graduates per program is shown in Figure 1. 
Figure 1: Number of Graduates by Program, 2017-2018 Academic Year

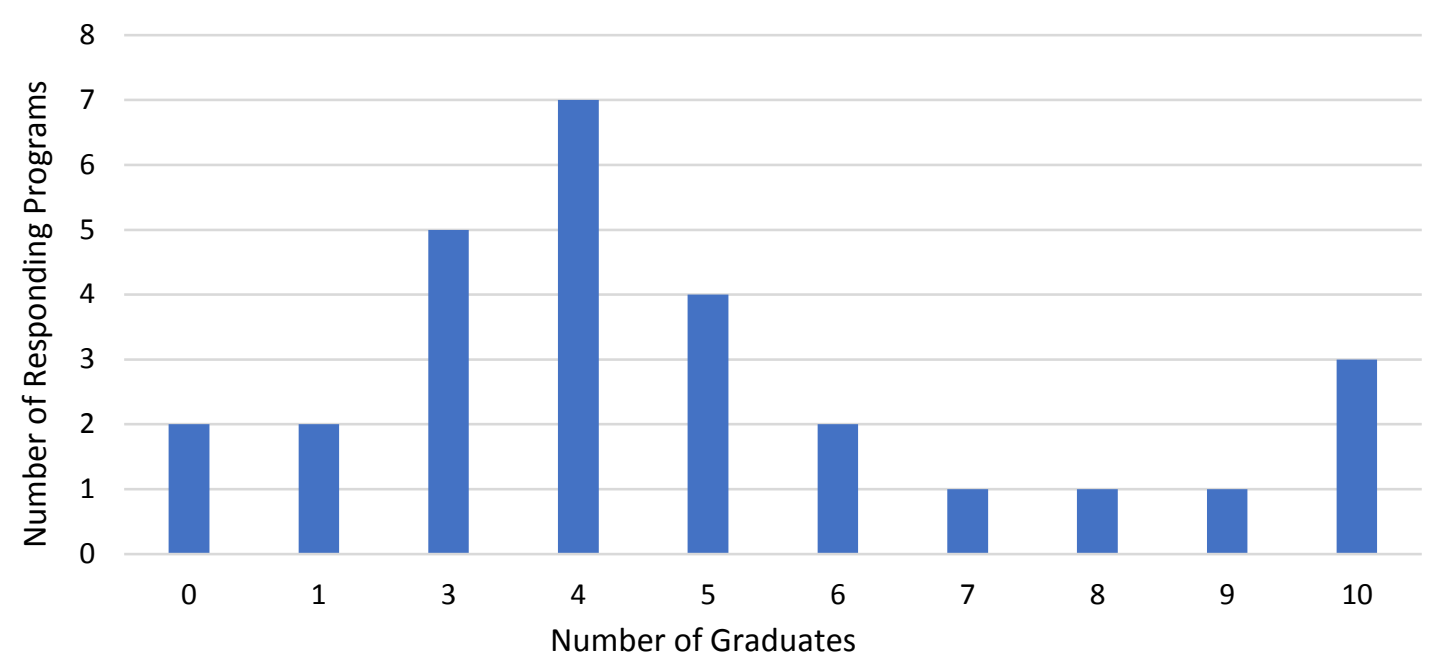

If the sample is representative of all programs, an estimated 294 new $\mathrm{PhDs}$ graduated during the 2017-2018 academic year. While representativeness cannot be guaranteed, Figure 1 shows no bias according to program activity or inactivity over the given year. Additionally, Appendix Table A1 shows geographic diversity among responding programs.

Respondents report that $46 \%$ of graduates (60 graduates in survey sample; estimated 135 total) accepted jobs at academic institutions. However, only 114 academic planning jobs were advertised via ACSP, and of those only 70 were open to new PhDs. The survey did not request data on job placement for graduates accepting non-academic positions.

Academic institutions advertised openings for 51 assistant professors, 6 post-doctoral scholars, 11 lecturers/instructors, and 2 researchers. Of the 51 assistant professor openings, 10 advertised for candidates at either the assistant or associate rank, which implies another reality of these job postings: some positions - both open rank and those advertising for the assistant level specifically - are filled by faculty moving from other institutions, rather than by new $\mathrm{PhDs}$. A final caveat here is that some positions may be filled by PhDs from allied fields such as Geography.

To bring the discussion into focus, according to the survey, approximately 135 new Planning PhDs took jobs at academic institutions, but the job postings show only 70 suitable openings, 51 of which were tenure-track. It necessarily follows that approximately half of new $\mathrm{PhDs}$ who took academic jobs accepted jobs we categorize some other way: staying at their alma mater for non-advertised post-docs or staff positions; taking adjunct/part-time teaching positions; accepting faculty positions in Departments of Geography or allied fields not captured in the ACSP database; international students engaging in Optional Practical Training (OPT) positions; etc. Less than one-fifth of new Planning PhDs accepted tenure-track jobs advertised through ACSP. Indisputably, Planning has a competitive academic job market.

\section{Specializations: Program Offerings versus the Job Market}

Planning is a broad field with specialized job openings, meaning that new $\mathrm{PhDs}$ generally do not apply for all open positions, but rather only those that align with their research area. Survey respondents identified the specializations offered in their PhD programs. The most popular 
specializations are Environmental and Sustainability Planning (18); Transportation, Land Use, and Urban Design (18); and Community Development (16). Figure 2 shows the frequency of other specializations.

Figure 2. Most Common Program Specializations

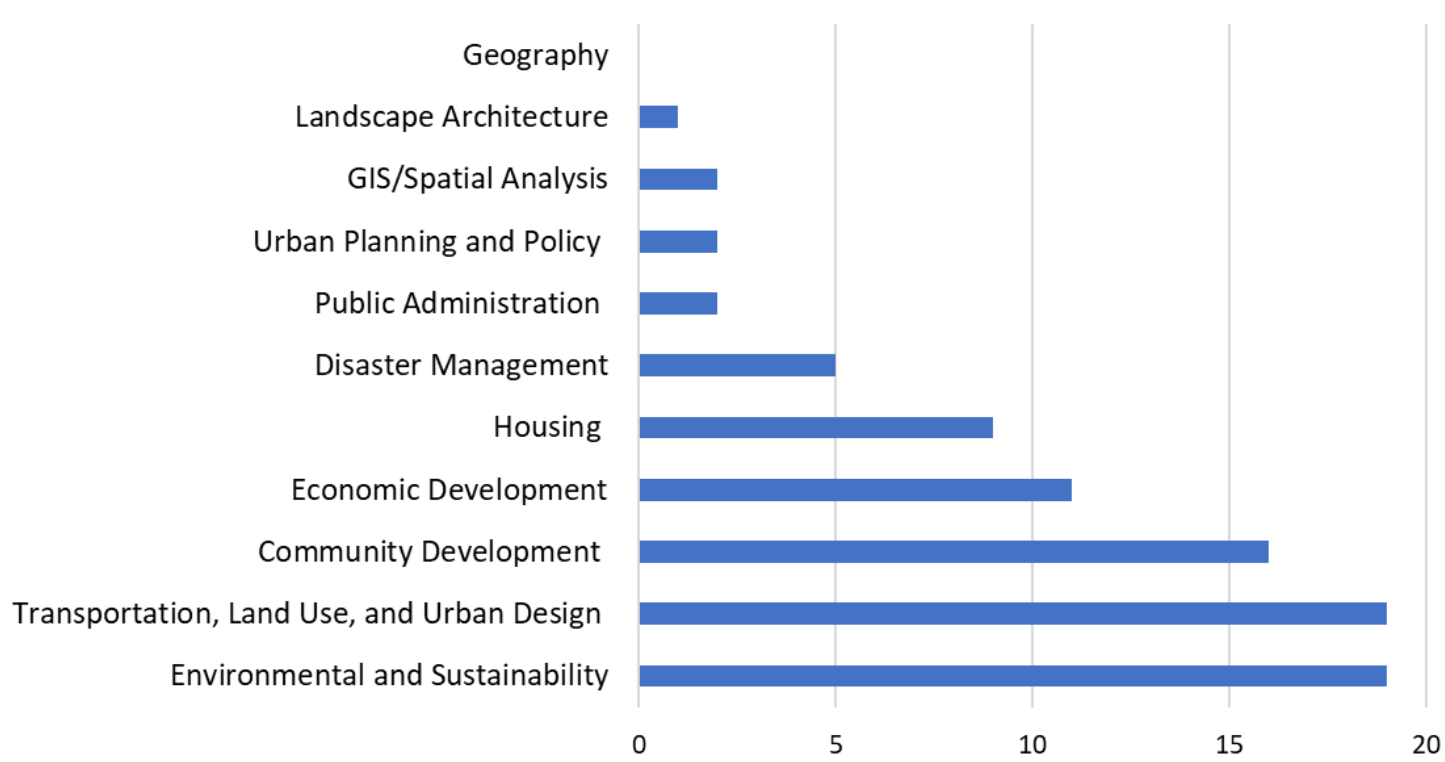

As shown through a comparison of Figures 2 and 3, the frequency of program specializations only partially aligns with the frequency of demand for those specializations. Both $\mathrm{PhD}$ program curriculum and the job market favor Environmental and Sustainability Planning, Transportation, Land Use and Urban Design, and Community Development. At the other end of the chart, Urban Policy ${ }^{5}$, GIS/Spatial Analysis, Landscape Architecture, and Geography are more common in job advertisements than in $\mathrm{PhD}$ programs. Only one surveyed program identified a specialization in Landscape Architecture and none in Geography.

However, this does not mean students lack access to specialized training in these subject areas, or that students are not qualified to apply for these positions. Many universities have departments of Geography and Landscape Architecture and Urban Policy is sometimes shared between Planning and Public Administration programs. Students may be able to seek coursework from those departments without recognition as a specialization. Further, $\mathrm{PhD}$ programs vary in terms of whether and how they require students to identify specializations. Some specializations may offer cross-training to other specializations; one example is economic development, which often also trains scholars in spatial analysis. Finally, many job advertisements list multiple potential specializations (as reflected in the horizontal axis of Figure 3). Candidates can apply for positions without demonstrating expertise in all preferred specializations in a given advertisement. In summary, Figures 2 and 3 should be interpreted cautiously in conclusions about skill matching between doctoral training and the job market.

\footnotetext{
${ }^{5}$ While Figures 2 and 3 indicate specializations in "Urban Planning and Policy," care has been taken to ensure this does not reflect the fact that programs may be named "Urban Planning" or that jobs are looking for faculty in "Urban Planning," but rather reflects that programs are specialized in Planning-related Urban Policy.
} 


\section{Figure 3. Specializations in ACSP Job Posts}

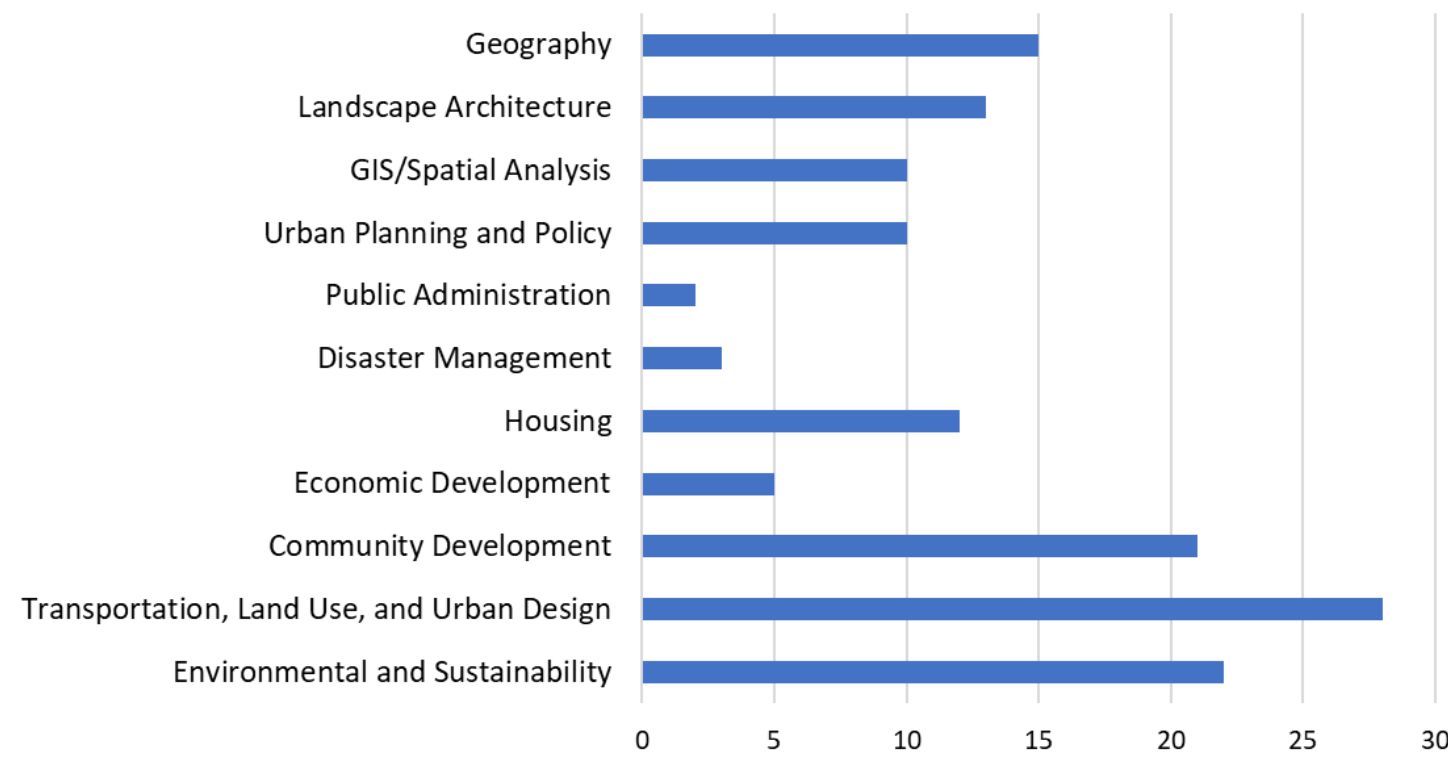

Graduate Education: Teaching and Research Experience of Graduates

While all programs offer some opportunities for students to gain teaching experience - another skillset often sought in job candidates - the extent of those opportunities varies significantly across programs (Figure 4). In a quarter of programs, all students gain teaching experience, and in nearly half of programs, most students gain teaching experience. In $29 \%$ of programs, these opportunities are relatively harder to come by.

Figure 4. How Many Students Get Teaching Opportunities?

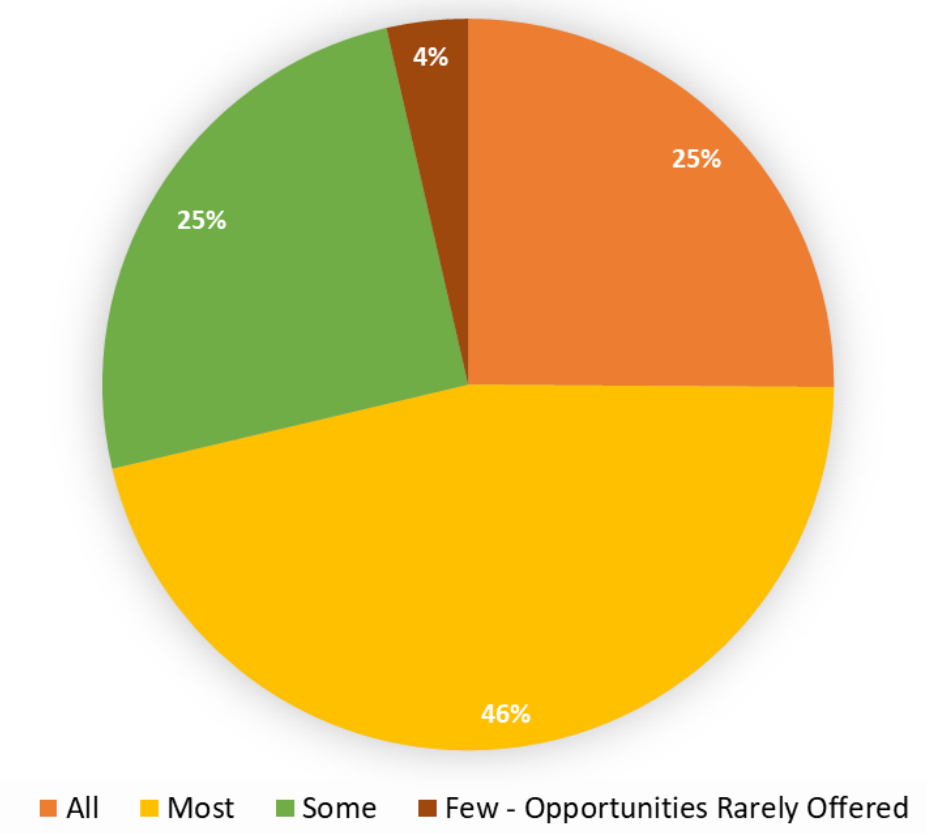

Respondents were asked to identify from a list the teaching tasks and responsibilities $\mathrm{PhD}$ students in their programs engage in: proctor and grade (26); act as instructor of record (22); lead discussion sections (20); secure TA positions in other departments (16); and, much less 
often, engage in curriculum design (9). Most of these TA experiences likely vary according to the supervising faculty member's expectations. However, permission to act as an instructor of record originates from a department chair, dean, or even university-level administration. That this occurs in 22/28 responding programs reflects a formal and widespread institutional commitment to doctoral student participation in instruction.

In addition to offering conventional teaching opportunities, Auburn University's $\mathrm{PhD}$ program offers a one-year teaching program. While virtually all tenure-track positions involve teaching, surprisingly only eight job announcements emphasized teaching as a required or preferred skillset. However, this should not be taken as evidence that teaching experience is not valued more broadly. The 2018-2019 compilation of the job bank data will collect more focused information on expectations about teaching experience.

Most $\mathrm{PhD}$ programs require students to produce publishable research (22). While students are typically encouraged to submit and publish their work, only the University of Utah and Texas A\&M University make publishing a requirement for graduation. Regardless, when asked to what extent students publish prior to graduation, the majority responded that most students do publish (16), and in three cases (University of Minnesota, University of Oklahoma and University of Utah) all students publish prior to graduation.

\section{Limitations}

First, it warrants mentioning that the survey data on the placement of graduates at academic institutions may not be fully reliable. An evaluation of my own institution's data revealed a difference in interpretation of the survey question between our survey respondent and myself. This question will be clarified in the coming year to ensure fully reliable results. In the case of Cleveland State University, more of our graduates, not fewer, accepted academic positions than we reported.

Second, as already identified, the seeming mismatch between program specializations and job market demands may not be as stark as the data suggest. Cross-training between specializations overcomes a portion of the apparent mismatch. Perhaps more significantly, though, the data represent what programs offer, not what students pursue. As such, the data on program specializations does not directly capture the skillsets of recent graduates.

Beyond these identified limitations, it bears noting that this report is based on only one year of data. The job market's preferred specializations likely fluctuate from year to year. The number of graduates also likely fluctuates from year to year. Fluctuations in both specializations preferred by the job market and number of graduates implies that the apparent job market mismatch will also fluctuate over time. Future versions of this report will use multi-year averages to smooth these fluctuations. Finally, a protocol is being developed to better record Planners 2040 Facebook job postings which are not captured by the ACSP job bank.

\section{Conclusion}

In summary, this research finds that over the 2017-2018 academic year, the academic job market in Planning was competitive. Our institutions graduated more new $\mathrm{PhDs}$ than were accommodated by the academic job market, and graduates filled more jobs than are even identifiable in public job postings. Programs graduated an average of $4.67 \mathrm{PhDs}$ during the year, yielding an estimated 294 new PhDs during the 2017-2018 academic year. Of these 
graduates, respondents report that $46 \%$ accepted positions at academic institutions. A total of 114 academic jobs were advertised through ACSP. Only 70 of these were open to new PhDs, and of those, only 51 were tenure-track, meaning that less than one-fifth of graduates accepted tenure-track positions advertised through ACSP. It follows that many new Planning PhDs accepted unadvertised positions or positions in allied departments. New PhDs from most programs enter the job market with both teaching experience and publications. While the specializations of open positions likely vary from year to year (which future editions of this report will discuss), the 2017-2018 job market favored Environmental and Sustainability Planning and in Transportation, Land Use and Urban Design. Taken together, the results point to a competitive academic job market in Planning.

\section{Acknowledgements}

I would like to thank all the program coordinators, department chairs, and others who participated in the survey this year. Your participation made possible this analysis and report back to our academic community. I would also like to especially thank Tim Green (Assistant Professor, Clemson University) for reviewing and providing feedback on an earlier version of this report.

\section{Author Biosketch and Contact Information}

Joanna Ganning is an Assistant Professor of Urban Planning and Economic Development in the Levin College of Urban Affairs at Cleveland State University. Her research focuses on urban and regional economic development, spatial econometrics, and shrinking cities. Previous research has been funded by the U.S. Department of Housing and Urban Development, the U.S. Department of Transportation through the National Institute for Transportation and Communities, the National Endowment for the Arts, and several state and local agencies. Previously, she served as an Assistant Professor and the Executive Director of the Metropolitan Research Center at the University of Utah.

Email: j.ganning@csuohio.edu

Phone: 216-687-2221

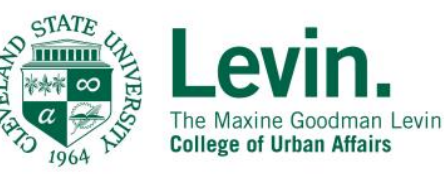




\section{Appendix}

Table A1: List of Contacted and Participating Institutions and Programs

Institution

Arizona State University*

Arizona State University

Auburn University*

Clemson University*

Cleveland State University*

Columbia University in the City of New York*

Cornell University

Florida Atlantic University

Florida State University*

Georgia Institute of Technology*

Harvard University

Jackson State University

Kansas State University

Massachusetts Institute of Technology*

Michigan State University*

New York University

Ohio State University*

Portland State University*

Rutgers University*

Texas A \& M University*

Texas Southern University

University at Buffalo

University of Alabama at Birmingham

University of California-Berkeley

University of California-Irvine

University of California-Los Angeles

University of Cincinnati

University of Colorado Denver

University of Delaware

University of Florida*

University of Georgia

University of Hawaii at Manoa

University of Idaho

University of Illinois at Chicago*

University of Illinois at Urbana-Champaign*

University of Louisville

University of Maryland

University of Massachusetts-Boston*

University of Michigan*

University of Minnesota*

University of New Orleans

University of North Carolina*

University of Oklahoma*

University of Pennsylvania*

University of Southern California*

The University of Texas at Arlington*

The University of Texas at Austin

University of Utah*

University of Virginia

University of Washington

University of Wisconsin-Madison

Virginia Commonwealth University

Virginia Polytechnic Institute and State University*

Indiana University

Northeastern University*

The New School

Queens University of Charlotte

University College London

University of Alberta

University of British Columbia

University of Manitoba

\section{Name of Program}

PhD in Urban Planning

PhD in Geography

PhD in Public Administration and Public Policy

$\mathrm{PhD}$ in Planning, Design, and the Built Environment

PhD in Urban Studies and Public Affairs

PhD in Urban Planning

$\mathrm{PhD}$ in City and Regional Planning

PhD in Public Administration

$\mathrm{PhD}$ in Urban and Regional Planning

$\mathrm{PhD}$ in City and Regional Planning

$\mathrm{PhD}$ in Architecture, Landscape Architecture, and Urban Planning

$\mathrm{PhD}$ in Urban and Regional Planning

$\mathrm{PhD}$ in Environmental Design and Planning

PhD in Urban Studies and Planning

$\mathrm{PhD}$ in Planning, Design, and Construction

$\mathrm{PhD}$ in Public Administration

$\mathrm{PhD}$ in City and Regional Planning

$\mathrm{PhD}$ in Urban Studies

$\mathrm{PhD}$ in Planning and Public Policy

$\mathrm{PhD}$ in Urban and Regional Science

$\mathrm{PhD}$ in Urban Planning and Environmental Policy

$\mathrm{PhD}$ in Urban and Regional Planning

$\mathrm{PhD}$ in Geography

$\mathrm{PhD}$ in City and Regional Planning

$\mathrm{PhD}$ in Planning, Policy, and Design

$\mathrm{PhD}$ in Urban Planning

$\mathrm{PhD}$ in Regional Development Planning

$\mathrm{PhD}$ in Design and Planning

PhD in Urban Affairs \& Public Policy

$\mathrm{PhD}$ in Urban and Regional Planning

$\mathrm{PhD}$ in Environmental Design and Planning

$\mathrm{PhD}$ in Urban and Regional Planning

$\mathrm{PhD}$ in Geography

PhD in Urban Planning and Policy

$\mathrm{PhD}$ in Regional Planning

$\mathrm{PhD}$ in Urban and Public Affairs

$\mathrm{PhD}$ in Urban and Regional Planning and Design

$\mathrm{PhD}$ in Regional Planning

$\mathrm{PhD}$ in Urban and Regional Planning

$\mathrm{PhD}$ in Public Affairs

$\mathrm{PhD}$ in Urban Studies

$\mathrm{PhD}$ in Planning

$\mathrm{PhD}$ in Planning, Design, and Construction

$\mathrm{PhD}$ in City and Regional Planning

$\mathrm{PhD}$ in Urban Planning and Development

$\mathrm{PhD}$ in Urban Planning and Public Policy

$\mathrm{PhD}$ in Community and Regional Planning

$\mathrm{PhD}$ in Metropolitan Planning

$\mathrm{PhD}$ in The Constructed Environment

$\mathrm{PhD}$ in Urban Design and Planning

$\mathrm{PhD}$ in Urban and Regional Planning

PhD in Public Policy and Administration

$\mathrm{PhD}$ in Planning, Governance, \& Globalization

$\mathrm{PhD}$ in Public Affairs

$\mathrm{PhD}$ in Public Policy

$\mathrm{PhD}$ in Public and Urban Policy

$\mathrm{PhD}$ in Geography and Planning

$\mathrm{PhD}$ in Planning Studies

$\mathrm{PhD}$ in Urban and Regional Planning

$\mathrm{PhD}$ in Community and Regional Planning

$\mathrm{PhD}$ in Design and Planning

* Denotes participating program 